\title{
Pelatihan Blended Learning bagi Guru Di Lingkungan Madrasah Tsanawiyah Negeri Sumber Bungur
}

\author{
Agus Subaidi ${ }^{1}$, Moh Zayyadi ${ }^{2}$, Sri Indriati Hasanah ${ }^{3}$, dan Durroh Halim ${ }^{4}$ \\ Universitas Madura ${ }^{1,2,3,4}$ \\ agus_math@unira.ac.id ${ }^{1}$,zayyadi@unira.ac.id ${ }^{2}$,indriati_math@unira.ac.id ${ }^{3}$, durrohhalim21@gmail.com ${ }^{4}$
}

\begin{abstract}
Not all teachers in Madrasah Tsanawiyah (MTs)'s public of Sumber Bungur have the ability to adapt to Information and Communication of Technology (ICT) development. Especially in the management of technology-based applications. Whereas with the rapid development of technology, teachers ' knowledge of technology must be mastered in order to support success in learning. The goal of this devotion is to introduce blended learning and motivate teachers to apply technology in learning. The participants of the devotion are representatives of the teacher teachers in the subjects at MTs Sumber Bunga as many as 14 people. Before the devotion carried out the participants were given Pretests aims to know the initial knowledge of participants related to the model of learning, utilization of ICT and blended learning, the result teachers are less utilizing ICT in learning and yet Know about blended learning. Whilethe results of the dedication gained data that the participants experienced an increase in knowledge about blended learning. Participants can also utilize the app Edmodo and quiz creator that supports teachers to apply blended learning. The poll stated that participants responded well to the implementation of devotion. They want to apply blended learning in learning after knowing its usefulness.
\end{abstract}

Keywords: Blended learning; Edmodo; Quiz Creator

\begin{abstract}
Abstrak
Tidak semua guru di Madrasah Tsanawiyah (MTs) Negeri Sumber Bungur memiliki kemampuan beradaptasi dengan perkembangan Information and Communication of Technology (ICT). Terutama dalam pengelolaan aplikasi berbasis teknologi. Padahal seiring perkembangan teknologi yang semakin pesat, pengetahuan guru tentang teknologi harus dikuasai agar menunjang keberhasilan dalam pembelajaran.Tujuan pengabdian ini adalah untuk mengenalkan blended learning dan memotivasi guru agar bias menerapkan teknologi dalam pembelajaran. Peserta pengabdian merupakan perwakilan dari guru pengajar mata pelajaran yang ada di MTs Sumber Bungur sebanyak 14 orang. Sebelum pengabdian dilaksanakan para peserta diberikan pretest bertujuan untuk mengetahui pengetahuan awal peserta terkait model pembelajaran, pemanfaatan ICT dan blended learning, hasilnya para guru kurang memanfaatkan ICT dalam pembelajaran dan belum mengetahui tentang blended learning. Sedangkan hasil pengabdian diperoleh data bahwa peserta mengalami peningkatan pengetahuan tentang blended learning. Peserta juga sudah bias memanfaatkan aplikasi edmodo dan quiz creator yang menunjang guru-guru untuk menerapkan blended learning. Hasil angket menyatakan peserta merespon baik terhadap pelaksanaan pengabdian. Mereka ingin menerapkan blended learning dalam pembelajaran setelah mengetahui kebermanfaatannya.
\end{abstract}

Kata Kunci: Blended learning; Edmodo; Quiz Creator 


\section{A. PENDAHULUAN}

Tantangan dan berbagai permasalahan dalam dunia pendidikan, dijawab oleh pemerintah melalui berbagai upaya peningkatan kualitas pendidikan. Diantaranya adalah menyusun dan menyempurnakan kurikulum pendidikan, peningkatan sarana dan prasarana, melaksanakan penataran guru, dan penerapan berbagai strategi pembelajaran. Salah satu upaya pemerintah yang dapat kita cermati sekarang ini adalah penerapan Kurikulum 2013 yang mengharapkan guru lebih pada berpusat pada siswa (student centered). Masalah pendidikan di Indonesia, yang sampai saat ini masih dirasakan adalah rendahnya kualitas pendidikan. Hal ini didukung oleh ditemukannya banyak siswa yang memperoleh angka hasil belajar rendah atau di bawah rata-rata yang telah ditetapkan (Dimyati dan Mudjiono, 2006). Sehubungan dengan hal itu, perlu diadakannya usaha untuk memperbaiki sistem pendidikan, dimana pendidikan hendaknya membekali siswa dengan berbagai kecakapan hidup dan kemampuan disposisi berpikir kritis dalam memecahkan berbagai masalah (Kurniati \& Zayyadi, 2018).

Tidak bisa dipungkiri bahwa motivasi memiliki fungsi yang penting dalam pembelajaran. Fungsi motivasi adalah mendorong timbulnya tingkah laku atau perbuatan, sebagai pengarah untuk mencapai tujuan yang diinginkan, dan sebagai penggerak tingkah laku. Dengan kata lain, motivasi adalah usaha untuk menyediakan kondisi tertentu sehingga seseorang ingin melakukan sesuatu sesuai dengan tujuan yang diharapkan (Nasution, 1995). Jika dikaitkan dengan prestasi belajar, sudah tentu motivasi dan prestasi belajar memiliki hubungan yang erat. Motivasi berprestasi merupakan suatu harapan untuk memperoleh kepuasan dalam penguasaan perilaku, sehingga mencapai tujuan yang diinginkan
(McClelland, 1955). Hal ini menunjukkan bahwa ada hubungan konkret antara motivasi dan prestasi, yaitu untuk memperoleh prestasi yang baik, tentu seseorang harus memiliki motivasi yang baik pula.

Terkait dengan rendahnya motivasi dan prestasi belajar siswa, dipandang perlu upaya perbaikan proses pembelajaran yaitu dengan menerapkan pembelajaran yang berpusat pada siswa (student centered). Salah satu alternatif pembelajaran dalam pandangan konstruktivis yang dapat diterapkan untuk meningkatkan keaktifan siswa adalah dengan menerapkan strategi pembelajaran blended learning. Sesuai namanya, blended learning adalah strategi pembelajaran yang memadukan pertemuan tatap muka dengan materi online secara harmonis (Noer, 2010). Thorne (2003) menggambarkan blended learning sebagai "It represents an opportunity to integrate the innovative and technological advances offered by online learning with the interaction and participation offered in the best of traditional learning. Keuntungan yang diperoleh melalui penerapan strategi pembelajaran blended learning adalah meningkatkan pedagogi, meningkatkan akses, fleksibilitas, dan meningkatkan efektivitas biaya (Graham, 2005). Moebs \& Weibelzahl (2006) mendefinisikan blended learning sebagai penggabungan antara online dan tatap muka dalam satu aktivitas pembelajaran yang terintegrasi. Blended learning adalah sebuah konsep yang relatif baru dalam pembelajaran yang disampaikan melalui campuran pembelajaran online dan tradisional (Bielawski \& Metcalf, 2003). Asumsi utama dari desain blended learning adalah (1)gabungan belajar tatap muka dan online, (2) pengoptimalan keterlibatan mahasiswa, dan (3) strukturisasi dan pengaturan ulang jam (Garrison \& Vaughan, 2008).

Dalam hal ini, Blended learning terdiri dari dua kata blended 
(kombinasi/campuran) dan learning (belajar). Makna asli sekaligus yang paling umum tentang blended learning mengacu pada belajar yang mengkombinasi atau mencampur antara pembelajaran tatap muka (face to face) dan pembelajaran berbasis komputer (online dan offline).

Kemajuan teknologi di abad 21 berkembang pesat. Berbagai kemudahan bisa didapatkan oleh siswa misalkan untuk mendapatkan informasi yang terkait dengan pelajaran. Para siswa tinggal mengakses melalui internet. Penggunaan alat-alat elektronik seperti handphone dan laptop bisa juga dimanfaatkan dalam pembelajaran. Oleh karena itu, guru harus mengikuti perkembangan teknologi dan menerapkan dalam pembelajaran agar tidak ketinggalan zaman, melalui blended learning diharapkan dapat meningkatkan motivasi dan prestasi yang baik pada siswa dalam pembelajaran. Hal ini juga sesuai dengan penggunaan media komputer sebagai media guru dalam pembelajaran (Zayyadi, dkk, 2017, 2019).

Berdasarkan analisis situasi dan tinjauan dari berbagai sumber informasi yang berkaitan dengan MTs Negeri Sumber Bungur 1) Keterbatasan sarana pendukung yang belum memadai. 2) Tidak semua guru memiliki kemampuan beradaptasi dengan perkembangan ICT, terutama dalam pengelolaan aplikasi berbasis teknologi. 3) Keterbatasan jaringan mengingat madrasah kami kesulitan dalam akses. 4) Minimnya daya dukung finansial, terutama dari peserta didik. Karena rendahnya tingkat ekonomi orang tua peserta didik, maka jumlah siswa pemilik laptop baru mencapai 5\% dari jumlah siswa seluruhnya. 5) Minimnya kesadaran ber-ICT. Orang tua yang notabene berasal dari keluarga mampu pun masih enggan untuk melengkapi kebutuhan ICT anak mereka. Kebanyakn dari mereka lebih mudah memfasilitasi anaknya dengan membelikan handphone mahal atau sepeda motor dari pada membelikan atau mengkredit laptop. 6) Minimnya pengetahuan masyarakat akan penggunaan dan manfaat ICT terhadap proses pembelajaran dan karir anak bangsa, jangankan berpikir untuk membeli laptop dan memasang internet, cara memakai dan mengoperasikan komputer saja mereka tidak tahu. 7) Minimnya kesadaran siswa dalam pengunaan media ICT secara bijak dan aman. Pada umumnya siswa menggunakan laptop atau internet untuk hal-hal yang kurang bermanfaat seperti facebookan, berkirim email yang tidak begitu penting, bahkan membuka situs-situs dan blog terlarang yang bukannya membawa manfaat namun justru merusak dan mendorong untuk berbuat maksiat. Minimnya perhatian dan kontrol pemerintah dalam mengawasi penggunaan internet dan memproteksi situs-situs berbahaya serta mengeliminasi para hacker peretas situs tersebut. Kalaupun ada pemblokiran pada beberapa situs berbahaya, namun ternyata tidak semua dari mereka terblokir karena masih banyak hacker yang dengan kepandaiannya berhasil membuka kembali situs tersebut untuk kepentingan sendiri maupun tindakan kriminalitas.

\section{B. PELAKSAAAN DAN METODE}

Metode dalam kegiatan ini adalah melakukan identifikasi permasalahan yang terjadi di sekolah terkait pembelajaran yang diterapkan di sekolah dan hasil belajar siswa. Kemudian setelah identifikasi, pengenalan program atau sosialisasi kegiatan pengabdian kepada sekolah-sekolah sasaran. Selanjutnya, pelaksanaan pengabdian dengan mengundang beberapa guru-guru untuk diberikan pelatihan tentang penerapan blended learning. Setelah itu, akan dilaksanakan pelatihan blended learning. Hal ini dilakukan untuk menjadikan pembelajaran yang berbasis blended benarbenar diterapkan di sekolahnya pada saat 
kegiatan belajar mengajar pembelajaran. Kegiata berikutnya melakukan mentoring langsung demi teciptanya pembelajaran yang berbasis blended learning. Terakhir, monitoring pada sekolah sasaran untuk melakukan evaluasi dan pembenahan apabila terjadi hal-hal yang tidak sesuai dengan apa yang dilakukan pada waktu pelatihan dan pendidikan pembelajaran berbasis blended.

\section{C.HASIL DAN PEMBAHASAN}

Pelatihan blended learning ini dilaksanakan di MTs Negeri SumberBungur. Peserta merupakan perwakilan guru-guru mata pelajaran yang ada di lingkungan setempat. Sebelum melaksanakan pengabdian peneliti memberikan pretes pada semua peserta yang berupa angket. Pemberian pretest bertujuan untuk mengetahui pengetahuan awal peserta terkait model pembelajaran dan blended learning. Melalui pemberian angket pada para peserta maka dapat mengetahui sejauh mana peningkatan pengetahuan selama pengabdian dilaksanakan (Subaidi \& Zayyadi, 2018). Peserta yang hadir dan mengisi pretest sebanyak 14 orang.

Hasil pretest menunjukkan bahwa semua peserta pernah mengikuti pelatihan atau workshop tentang model-model pembelajaran, menggunakan model yang bervariasi dalam setiap pertemuan/pembelajaran, dan para guru juga merespon bahwa penggunaan model pembelajaran dapat mempengaruhi prestasi belajar siswa. Namun dari 14 guru tersebut ada 1 guru yang merespon tidak pernah memanfaatkan ICT dalam pembelajaran seiring perkembangan zaman yang semakin modern yaitu guru penjaskes (olahraga). Meskipun mayoritas guru sudah pernah menggunakan ICT, tetapi yang pernah melaksanakan pembelajaran online hanya 4 guru. Contoh pembelajaran online yang sudah diketahui oleh guru-guru tersebut yaitu google form, ruang guru, penugasan melalui WA dan penilaian harian berbasis CBT. Sebanyak 10 guru merasa perlu untuk mengkombinasikan tiga sumber belajar yaitu pembelajaran tatap muka, offline, dan online. Semua peserta belum mengetahui tentang blended learning. Berikut Tabel hasil pretest dari peserta pelatihan.

Tabel 1. Angket sebelum Melaksanakan Pengabdian

\begin{tabular}{|c|c|c|c|}
\hline \multirow{2}{*}{ No } & \multirow{2}{*}{ Pertanyaan } & \multicolumn{2}{|c|}{ Jawaban } \\
\hline & & Ya & Tidak \\
\hline 1 & $\begin{array}{l}\text { Apakah Bapak/Ibu pernah } \\
\text { mengikuti pelatihan atau } \\
\text { workshop tentang model- } \\
\text { model pembelajaran? }\end{array}$ & 14 & \\
\hline 2 & $\begin{array}{l}\text { Apakah Bapak/Ibu } \\
\text { menggunakan model yang } \\
\text { bervariasi dalam setiap } \\
\text { pertemuan/pembelajaran? }\end{array}$ & 14 & \\
\hline 3 & $\begin{array}{lr}\text { Apakah penggunaan } & \text { model } \\
\text { pembelajaran } & \text { dapat } \\
\text { mempengaruhi } & \text { prestasi } \\
\text { belajar siswa? } & \\
\end{array}$ & 14 & \\
\hline 4 & $\begin{array}{l}\text { Apakah Bapak/Ibu pernah } \\
\text { memanfaatkan ICT dalam } \\
\text { pembelajaran } \\
\text { perkembangan zaman yang } \\
\text { semakin modern? }\end{array}$ & 13 & 1 \\
\hline 5 & $\begin{array}{l}\text { Apakah Bapak/Ibu pernah } \\
\text { melaksanakan pembelajaran } \\
\text { online? }\end{array}$ & 4 & 10 \\
\hline 6 & $\begin{array}{lr}\text { Menurut Bapak/Ibu, perlukah } \\
\text { mengkombinasikan tiga } \\
\text { sumber belajar yaitu } \\
\text { pembelajaran tatap muka, } \\
\text { offline, dan online? }\end{array}$ & 10 & 3 \\
\hline 7 & $\begin{array}{l}\text { Apakah Bapak/Ibu } \\
\text { mengetahui tentang Blended } \\
\text { learning? }\end{array}$ & & 14 \\
\hline
\end{tabular}

Pada saat pelaksanaan pelatihan, antusiasme peserta luar biasa terlebih dengan adanya pemberian motivasi dari narasumber untuk meningkatkan pengetahuan tentang blended learning. Peserta rajin bertanya tentang blended learning dan penggunaan 
aplikasi dalam blended learning berupa aplikasi Quiz Creatordan Edmodo.Pelaksanaan pelatihan dimulai dengan pemaparan tentang blended learning oleh narasumber Moh.Zayyadi, M.Pd. dosen Universitas Madura dan dilanjutkan dengan pemaparan aplikasi Quiz Creator dan Edmodo oleh narasumber Durroh Halim dari mahasiswa prodi pendidikan matematika Universitas Madura. Pada saat pemaparan tentang penggunaan aplikasi, peserta langsung dipandu untuk praktek langsung dengan menggunakan laptop masing-masing peserta. Gambar berikut menunjukkan pelaksanaan pelatihan.

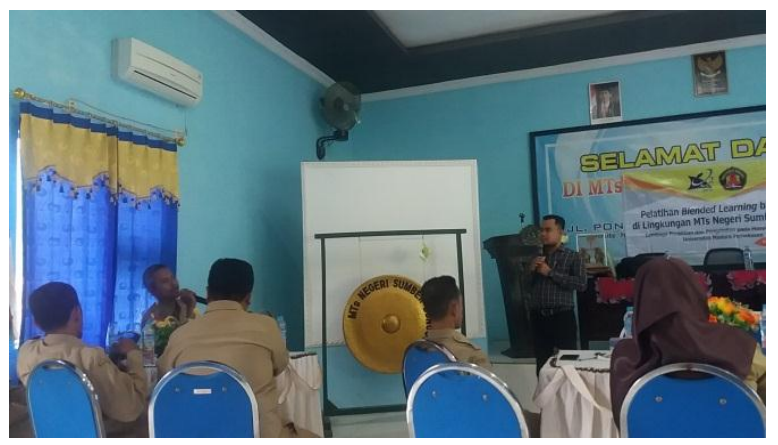

Gambar 1. Kegiatan Pelaksanaan Pengabdian Masyarakat

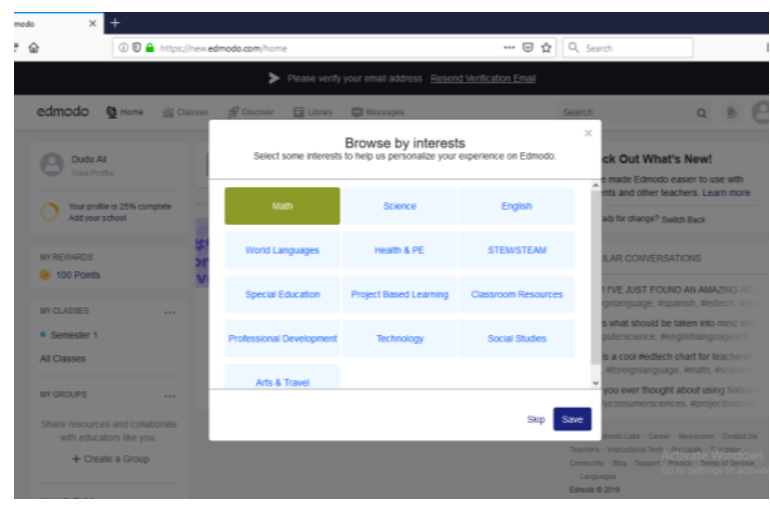

Gambar 2.Tampilan Hasil Edmodo

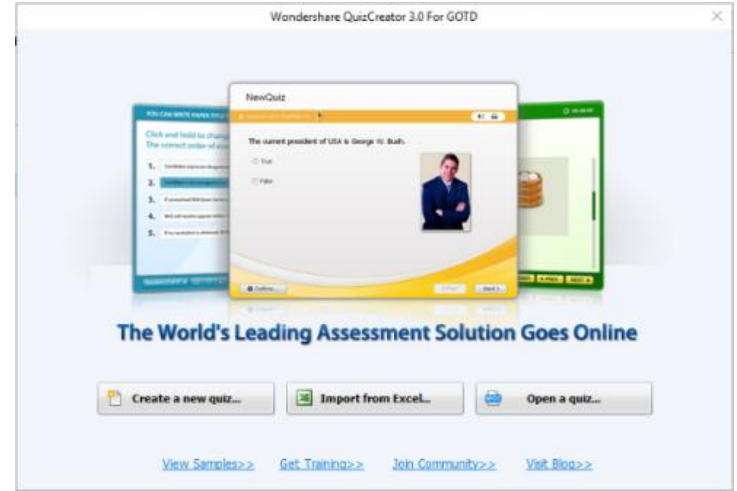

Gambar 3.Tampilan Quiz Creator

Pada akhir pelatihan para peserta mengisi angket kembali untuk mengetahui respon mereka setelah diberikan penjelasan tentang blended learning dan aplikasi Quiz dan Edmodo. Berdasarkan hasil angket kami mendapatkan hasil sebagaimana tabel berikut.

Tabel 2. Angket setelah Melaksanakan Pengabdian

\begin{tabular}{|c|c|c|c|}
\hline \multirow{2}{*}{$\begin{array}{l}\mathbf{N} \\
\text { o. }\end{array}$} & \multirow{2}{*}{ Pertanyaan } & \multicolumn{2}{|c|}{ Jawaban } \\
\hline & & Ya & Tidak \\
\hline 1 & $\begin{array}{l}\text { Apakah kegiatan yang } \\
\text { dilaksanakan sesuai dengan } \\
\text { tujuan yang ingin dicapai yakni } \\
\text { meningkatkan pengetahuan } \\
\text { guru tentang Blended learning } \\
?\end{array}$ & 12 & \\
\hline 2 & $\begin{array}{lr}\text { Apakah Blended } & \text { learning } \\
\text { bermanfaat } & \text { dalam } \\
\text { pembelajaran? } & \end{array}$ & 12 & \\
\hline 3 & $\begin{array}{l}\text { Apakah Blended learning } \\
\text { dapat diterapkan dalam mata } \\
\text { pelajaran yang Bapak/Ibu ajar } \\
\text { ? }\end{array}$ & 12 & \\
\hline 4 & $\begin{array}{l}\text { Apakah fasilitas sekolah dan } \\
\text { siswa di tempat Bapak/Ibu } \\
\text { mengajar mendukung untuk } \\
\text { dilaksanakan Blended learning } \\
\text { ? }\end{array}$ & 12 & \\
\hline 5 & $\begin{array}{lr}\text { Apakah } & \text { Bapak/Ibu } \\
\text { berkeinginan } & \text { untuk } \\
\text { menerapkan } & \text { Blended learning } \\
?\end{array}$ & 12 & \\
\hline 6 & $\begin{array}{lrr}\text { Apakah Bapak/Ibu akan } \\
\text { memperdalam pengetahuan } \\
\text { tentang Blended learning } \\
\text { dengan } & \text { mengikuti } \\
\text { workshop/pelatihan } & \text { yang } \\
\text { sejenis? } & \end{array}$ & 12 & \\
\hline
\end{tabular}


Terlihat pada Tabel 2 jumlah responden sebanyak 12 orang. Berkurangnya jumlah peserta pelatihan dikarenakan beberapa peserta memiliki kegiatan lain yang tidak bisa ditinggal pada saat itu. Tetapi hal itu tidak menjadi menurunnya semangat peserta yang lain. Respon peserta menunjukkan kesemuanya mengalami peningkatan pengetahuan khususnya tentang blended learning dan menganggap bermanfaat dalam pembelajaran. Selain itu, blended learning dapat diterapkan dalam mata pelajaran yang masing-masing mereka ajar, mereka ingin menerapkan blended learning bahkan ingin memperdalam pengetahuan tentangnya dengan mengikuti workshop/pelatihan yang sejenis. Bahkan mereka ingin mendesiminasikan pada guru lain dalam kegitan MGMP.

Komentar- komentar dari peserta adalah 1) blended learningdapat membantu guru mempermudah dalam proses pembelajaran terlebih dengan adanya aplikasi pada saat ujian tidak perlu mengoreksi karena nilai langsung keluar, 2) blended learningsangat berimplikasi dengan program madrasah yang melayani siswa dengan layanan SKS melalui pendekatan pembelajaran berbasis UKBM, 3) blended learningmemungkinkan terjadinya interaksi pembelajaran tanpa harus bertatap muka langsung di dalam kelas, 4) siswa dapat menambah pengetahuan dari berbagai sumber. Komentar-komentar para peserta sejalan dengan peneliti-peneliti seperti Johnson \&Marsh, Singh \& Reed, Whittaker (Sujana, dkk, 2019) tentang kebermanfaatan blended learning yakni blended learning dapat meningkatkan efektivitas pembelajaran, memperluas jangkauan pembelajaran, efisiensi waktu dan biaya dan meningkatkan capaian akhir.

\section{Simpulan}

\section{PENUTUP}

Kegiatan pengabdian ini telah berhasil dilaksanakan di MTs Negeri Sumber Bungur dengan pesertanya guru-guru perwakilan dari setiap mata pelajaran. Peserta mengalami peningkatan pengetahuan tentang blended learning. Peserta juga sudah bias memanfaatkan aplikasi edmodo dan quiz creator yang menunjang guru-guru untuk menerapkan blended learning. Hasil angket menyatakan peserta merespon baik terhadap pelaksanaan pengabdian. Mereka ingin menerapkan blended learning dalam pembelajaran setelah mengetahui kebermanfaatannya

\section{Saran}

Saran yang dapat diberikan dari kegiatan ini: 1) Sebaiknya sediakan waktu yang cukup dalam pelatihan. 2) Perlu ketersediaan sarana pendukung aplikasi (jaringan internet/wifi) untuk kemudahan peserta menjalankan aplikasi. Dan 3) Perlu kegiatan lanjutan dari kegiatan pelatihan ini untuk mengawal pelaksanaan blended learning di sekolah untuk menghasilkan dampak yang nyata dari pengabdian.

\section{Ucapan Terima Kasih}

Tim pelaksana pengadian
menyampaikan terima kasih kepada
Lembaga Penelitian dan Pengabdian
Masyarakat Universitas Madura yang telah
memberikan dana hibah dalam pelaksanaan
pengabdian ini.

\section{E. DAFTAR PUSTAKA}

Bielawski, L \& Metcalf, D. 2003. Blended eLearning: Integrating Knowledge, Performance Support, and Online Learning. Amherst, MA: HRD Press. 
Dimyati dan Mudjiono, 2006. Belajar dan Pembelajaran. Jakarta: PT. Rineka Cipta.

Garrison, D.R. \& Vaughan, N.D. 2008. Blended Learning in Higher Education. San Francisco: JosseyBass.

Graham, C. R. 2005. Blended learning system: Definition, current trends and future direction. In: Bonk, C. J., Graham, C. R. (eds.) Handbook of Blended Learning: Global Perspectives, Local Designs, pp.3-21. San Francisco: Pfeiffer.

Kurniati, D., \& Zayyadi, M. 2018. The Critical Thinking Dispositions of Students around Coffee Plantation Area in Solving Algebraic Problems. International Journal of Engineering \& Technology, 7(2.10), 18-20.

McClelland, D. C. (Ed.). 1955. Studies in motivation. East Norwalk, CT, US: Appleton-Century-Crofts.

Moebs, S. \& Weibelzahl, S. 2006. Towards a good mix in blended learning for small and medium sized enterprises. Outline of a Delphi Study. Proceedings of the Workshop on Blended Learning and SMEs held in conjuction with the 1st European Conference on Technology Enhancing Learning Crete, Greece, pp 1-6.

Nasution. 1995. Dikdaktik Asas-asas Mengajar. Jakarta: Bumi Aksara.
Noer, M. 2010. Blended Learning Mengubah Cara Kita Belajar di Masa Depan. (Online). (http://www.muhammadnoer.com/201 0/07/blended-learning-mengubahcara-kita-belajar-di-masa-depan.

Subaidi, A \& Zayyadi, M. 2018. Pelatihan Strategi Pengembangan Perpustakaan Sekolah Tingkatan Menengah SeKecamatan Tlanakan, JPM (Jurnal Pemberdayaan Masyarakat). 3(1). 252-258.

Sujana, I.M., Waluyo, U., Soepriyanti, H., dan Arifuddin. 2019. Workshop Pengembangan Blended learning Berbasis Google Classroom (GC) sebagai Solusi Pembelajaran dan Penelitian Tindakan Kelas (PTK). Jurnal Pendidikan dan Pengabdian Masyarakat.2. (1).

Zayyadi. M. Supardi, L, 2017. Pemanfaatan Teknologi Komputer Sebagai Media Pembelajaran Pada Guru Matematika. Jurnal Pengabdian Masyarakat Borneo 1(2) 25-30.

Zayyadi, M. Lanya, H \& Irawati, S. 2019. Geogebra dan Maple Sebagai Media Pembelajaran Matematika untuk Meningkatkan Kualitas Guru Matematika. Abdimas Dewantara. 2(1).53-61 